\section{INTERVIEW WITH STEVE CALLENDER}

INTERVIEW BY ROGER GROS

Roger Gros is the publisher of Global Gaming Business and is based in Las Vegas, Nevada, and Atlantic City, New Jersey.

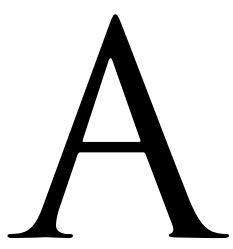

s senior vice president of eastern operations for Caesars Entertainment, Steve Callender oversees four Atlantic City casinos: Tropicana, Caesars Atlantic City, Harrah's Resort and Bally's. Complicating matters was the pending deal between Eldorado Resorts and Caesars Entertainment, which wasn't finalized until mid-July. Callender has a long history of working for Atlantic City casino companies, but his position was elevated when Eldorado bought Tropicana Entertainment in 2017.

ROGER GROS: I want to go over what happened during the shutdown and prior to the shutdown, and also how you reopened. Let's start with the guidance that you got from the regulators when the shutdown order was given. How closely did you work with the Division of Gaming Enforcement (DGE) and the Commission at that point?

STEVE CALLENDER: Very, very closely. They are great communicators, and they walked us through what they would like to see happen. We had to do this before, unfortunately, so it was easy to get done. Everybody was communicating and coordinating together. It was seamless, really.

ROGER GROS: New Jersey was fortunate in that we have been through that before, but mostly legislative problems, not as serious as this. The fact that you had done it before was probably an advantage.

STEVE CALLENDER: Right. Director Rebuck works very well with our organizations.

ROGER GROS: No question about that. What was your strategy to stay in touch with your customers throughout the lockdown? At first we thought it was going to be two weeks or so, and it stretched out to be closer to four months. How did you stay in touch with your customers during that time?

STEVE CALLENDER: We updated our website regularly, and we kept some sales staff on to talk to folks and make some phone calls. We did a lot of emailing. Frankly, Roger, a lot of people called us. We were probably fielding 4 or 5,000 calls a month while we were closed, the whole time we were closed.

People were interested in when they were going to be able to come back to enjoy their time here, and we did our best to communicate with them, and that was really the best way to do it.

ROGER GROS: Was there any interest in online gaming at that point? I know Tropicana has a great site, as well as the Virgin sites. Did you have any discussions about that with your clients?

STEVE CALLENDER: We did. We made that available, and our numbers went through the roof. They continue to stay strong. Even once the bricks-and-mortar reopened, our online numbers are very, very strong. People gravitated to it in a way that they had not before.

It is a great site, TropicanaEntertainment.com, but we did not see people going back and forth too much before the shutdown. They were either land-based customers, or they were online. Now a lot of people enlisted into the online space, and they are doing well with it.

ROGER GROS: More importantly, for the internal operations here, how did you stay in contact and engage with your employees through this period?

STEVE CALLENDER: We have a portal set up for our employees so that they can call in and find out what the latest updates are, and we kept it intact and updated so that they could get information about what was happening here.

We had a skeleton staff on board, around 100 people, between security and surveillance and some of our tradespeople, and we were doing a lot of cleaning. 
ROGER GROS: As I said, the reopening date kept getting further and further back. So how did you prepare for that, not knowing when it was actually going to occur?

STEVE CALLENDER: It was difficult. We programmed out what we thought was going to happen, looked at numbers, and had to keep changing things, unfortunately. We had certain time frames, we wanted to bring people back before we were going to be able to open. Unfortunately, we were guessing a little bit how to get there. We just hung in there and did our best.

ROGER GROS: How much of a curveball was the no-indoor-dining stipulation that Governor Murphy added at the last minute, right before you opened?

STEVE CALLENDER: That was a tough one. I am not going to lie to you. We expected to bring back a lot more team members, and without food and beverage, it just became impossible for us. I hear that was a big hit for Bob McDevitt (president of UNITE HERE Local 54 hospitality workers) and his team. We would love to get those folks back.

It was a big hit. A lot of people, they would come if they could eat, have dinner here, and drink. But it has hurt us in getting people back.

But we handled our protocols very well. We have not had any major problems. Maybe it is just as well that we did not have as many people. We are certainly not hitting the financial numbers that we were hoping to or need to. But the good news is we are doing things right, and hopefully we will be recognized for that, and we will get at least limited indoor dining or drinking on the floor at some point.

ROGER GROS: How have you responded to that in terms of outdoor dining? You have got some nice decks and some pool areas. Have you set up outdoor dining up there?

STEVE CALLENDER: We have. Over at Harrah's, the Gordon Ramsay Steakhouse is doing al fresco under the stars on the pool rooftop at Harrah's, which is terrific, and Bally's has a Guy Fieri Rooftop Chop. That is working out well. And we are using the Chelsea Pool Deck near Tropicana. We can feed a lot of people safely there and maintain social distancing. That is working out well.
Because of the boardwalk, our partners are Chickie's \& Pete's, Hooters, George Siganos, Casa Taco, and Tony Luke's. Initially it was tough. People had to wait quite a long time to get a seat. As more places have opened across the city, we are finding the ability to take care of more people and get them fed. It is helping us increase our numbers a little bit.

ROGER GROS: The casino environment is unlike it was previous to the shutdown. How have your customers responded? Have they kind of gotten used to the stipulations now, like every other slot machine turned off, that kind of thing?

STEVE CALLENDER: They have. It is difficult, but they are helping us. If you walk by them, they will say, "Hey, that guy over there, he pulled his mask down." They are letting us know what is going on, and we want to keep everybody as safe as possible. We are following our protocols. Our team is on board $100 \%$, and guests know it is not normal, but they want to be here, and they are doing their best to enjoy themselves.

ROGER GROS: How are you planning for the future in terms of spacing out the slot machines? At both Tropicana and Caesars, you had already started to reduce the casino floor size before this started. Are you bringing up plans to realign the slot machines and things of that nature on the casino floor?

STEVE CALLENDER: We have done some of that just because we want to make sure we have as many games as possible that people want to play. So, we had to move some games around. Obviously, some games are more popular than others. We are taking all that into consideration.

Going forward, since we got the deal done, we have made an agreement to spend a lot of capital in the Caesars and Harrah's and Tropicana properties. The plans will be taken into consideration as we figure that out and decide what we want it to look like.

ROGER GROS: Entertainment is off at all casinos, but that was always a big part of Caesars and Tropicana and Harrah's, for that matter. Do you have any idea of how that will return in terms of when they allow 25 or $50 \%$ occupancy?

STEVE CALLENDER: That is a great question, and we would love to get entertainment back. It is so 
important. It is vital to us, to our success, and we are actually looking over at Harrah's maybe doing some outdoor entertainment. We have a lot of space over there.

But a place like Caesars and Tropicana, it is going to be a lot more difficult. We are doing our best to plan things out and hoping that we get to a point where we can step in and have some social distancing in our show rooms.

ROGER GROS: At Harrah's you have got all that great space behind the property, next to the new convention center, that you built out there. That would be a real interesting opportunity to put some entertainment out there.

STEVE CALLENDER: Yeah, you have to think outside the box when times like this come along. We will see what happens.

ROGER GROS: New Jersey now seems to be one of the states where the pandemic has subsided a bit. How long do you expect to have to operate under the current stipulations before they start to be relaxed?

STEVE CALLENDER: Frankly, I have not asked anybody how long we have to do this. We just make sure that everybody is following the rules as best as they can so that it is recognized by the Governor's Office, and he feels that the number of COVID cases are going strongly enough in the right direction for us to get some expanded business, so that we can have some limited dining and have some indoor food and beverage. We will continue down the track that we are on, and we are always hoping for the best.

ROGER GROS: How did the deal between Eldorado and Caesars, which had not been completed during the shutdown, and was only completed about a month ago now, how did that affect what you were doing during the lockdown?

STEVE CALLENDER: It really did not have any effect on us in the properties here. I am sure the senior leadership team was, obviously, working with the Caesars team to try to get the deal done. But nobody thought the deal was going to get done when we were all closed.

We focused on our opening protocols, along with the rest of the properties. The casino association was meeting almost daily to get our protocols to the point where the Division of Gaming Enforcement would be confident enough in what we had proposed to take it to the Governor's Office.

We worked closely with AtlantiCare, who is our local health provider, and UNITE HERE to try to address as many issues as we could so that we felt comfortable that we could open safely. These properties are so big, our HVAC systems are so robust, and we have so much personnel here from a security standpoint, from a cleaning standpoint, and from a surveillance standpoint that they could trust that we could handle this without something terrible happening. That is really what is going on.

We are focused on what we could control, and that is what we did.

ROGER GROS: It sounds like most of the visitors, and certainly the employees, are taking the protocols seriously.

STEVE CALLENDER: Yes, they are. Very much so. I am not sure if they are just being respectful or they are afraid of getting sick. We tell them, "Mask up," and we get very little pushback.

There is a one-off here and there in every property. But for the most part, the employees and the guests have worked well together and done what we asked.

ROGER GROS: I just read the other day that the bill in the legislature that would give some tax relief to the casinos has been hung up. Is that really crucial to moving forward in Atlantic City?

STEVE CALLENDER: It really is, Roger. It is very important that this gets passed. You know, we have never had to ask for help before, but frankly, it is a shame. We had great momentum going in town. We went almost two years raising revenue every month, and obviously online gaming and sportsbook were a big part of that.

But momentum is momentum. When you are doing well, you like to keep it going. Unfortunately, we got stopped. We are going to have to spend in this in order to get our momentum back. People are playing somewhere else right now. If we want to get them down here, we are going to have to spend a little bit more on the marketing end than we are used to.

We certainly want to get more of our team members back to work, so that is important for us. People come 
to these places because of relationships with employees, and when all the employees are not here, that hurts us. There are people used to coming in and seeing folks that they know that work in a variety of different jobs.

They are not just hosts or executives. They are dealers, they are bartenders, and they are guest room attendants and security people. It is crucial that we get some support in order to get ourselves back to the levels we were operating at before this happened.

ROGER GROS: No question about that. Joe Lupo (president and CEO of Hard Rock Atlantic City) was telling me that he has been really encouraged by the Atlantic City Casino Association, that you have done a great job of getting people all on the same page, and that has not always been the case with the Association. But he says you have been doing a great job. What does that mean to you, to really be able to communicate with all the other CEOs in town?

STEVE CALLENDER: Well, it is nice of Joe to say that. A lot of the time leadership is about who you are leading, and they are a great group. There is a lot of talent there, a lot of experience.

Generally, the Casino Association meets once a month, and sometimes that is just on the phone. In the midst of this, we were meeting almost daily. I really appreciate everything they did. Bessie Sacco is legal counsel here, and she did most of the heavy lifting. Joe Dougherty was a big help for us.

But the leadership in these casinos, they are strong, all of them. They all have great opinions, and it was really a team effort to get us through this. There is a lot of smart people, and it was impressive. Again, the Commission and the Division worked with us to try to get us to this point, and we were happy to get it done.
ROGER GROS: Meetings and conventions have always been a big part of the Atlantic City business. The new convention center at Harrah's is spectacular. You have got a lot of space at Tropicana. Caesars has a bunch of space, not to mention the convention center itself. How long do you think that is going to take to come back?

STEVE CALLENDER: I wish I knew the answer to that because you are right, that is a big loss for us. That is happening in Las Vegas, as well.

I wish I could tell you. That is one of the things that might have to wait for a vaccine to come along and be effective before we can get big groups back again.

A lot of those groups are repeat groups, and we have relationships with them. Initially, we would just reschedule them, and nobody thought it was going to take this long or be at this level. We will stay in touch with those people. We will work with them. We are trying to be as friendly as we can in terms of not burning bridges and making sure at some point we get that business back. It is a great business for us.

The city is built for it. Especially with Ocean Casino and Hard Rock reopening, we have enough rooms in town now that we can handle big groups, and that hurts all of us, not having that business.

We are all focused on it, and if the ability comes along that we can do it again, we will be all over it.

ROGER GROS: Steve, thanks for the time. I really appreciate it. I am looking forward to seeing the properties and how you guys are doing.

STEVE CALLENDER: Thanks for letting me be part of this. I appreciate all the support you gave to Atlantic City over all these years. It is appreciated. 